\title{
Gender and CMC: A review on conflict and harassment
}

\author{
Qing Li \\ University of Calgary, Canada
}

\begin{abstract}
This paper reviews the literature related to gender and communication in $\mathrm{CMC}$ environments. A brief summary of gender related literature concerning general communication patterns in CMC is outlined first, to set the stage. Then, a review of literature in gender and $\mathrm{CMC}$ with a specific focus on conflict and harassment is presented. Comments upon this diverse body of work and recommendations concerning possible areas for future research are offered.

The focus on content and communicative practices in CMC highlights the possibilities of new gendered identities being constructed through online interactions. These new gendered identities may appear in a different form from the more fixed forms of "real life." In particular, the research reviewed in this paper regarding harassment, along with previous studies, leads "one to conclude that the 'democratic' perception of CMC is seriously flawed".
\end{abstract}

\section{Introduction}

The use of the Internet has increased dramatically in recent years; consequently, computer mediated communication (CMC) has attracted more and more researchers' attention. Although CMC technology, contents and usage patterns are still in a process of rapid change, the use of CMC as a teaching and learning tool is increasing dramatically. Among numerous research topics, one interesting issue concerns the effect of gender. In this paper, the literature related to gender and communication in CMC environments with respect to conflicts and harassments is reviewed.

When CMC was introduced, there was much excitement among researchers and practitioners. Many educators and researchers had high hopes for $\mathrm{CMC}$, believing that it provided more equal access to information and communication and would ultimately lead to greater equity (Grabe \& Grabe, 2001). Is it true that CMC is a gender equaliser? Findings from research are mixed. "There have been many claims made by disparate groups and institutions... which have claimed that $\mathrm{CMC}$ based interactions 
lack the overt structures of inequality found in other communicative situations" (Yates, 1997:281). In contrast, others believe that CMC brings out the worst aspects of male behaviour and gender relations, such as conflicts and harassment, due to the lack of face to face cues (Kiesler, Siegel \& McGuire, 1984). Some research findings (Herring, 1993; Li, 2002, 2002a; Yates, 1997) suggest that gender differences and their social consequences persist in computer mediated networks. That is, CMC reflects the same gendered identities and practices, as opposed to the claims that CMC provides an environment "free of the power structures of face to face interactions" (Yates, 1997:287).

These mixed findings call for and even force scholars to re-evaluate the very nature of the human communication process and to emphasise the importance of gender related issues in CMC (Soukup, 1999). As the Internet is increasingly being introduced into K-12 settings, numerous critical questions remain to be answered. In order to create a successful, effective, and gender inclusive learning environment using this powerful technology, we first need to have a thorough understanding of gender differences in the CMC context.

Earlier reviews of the literature (Yates, 1997, 2001) which deal with gender difference in relation to communication in CMC environments have been helpful in defining the organisation of the field, and in identifying the relevant studies. These earlier reviews concentrate, however, on topics related to language patterns that have been quite commonly addressed in the research field. No comprehensive review of the literature has been found that deals explicitly with gender issues in relation to harassment. The topic "at first glance seem to provide a confused, if not conflicting, set of results" (Yates, 2001). The purpose of this paper, therefore, is to summarise research on gender and communication focusing on conflict and harassment. This is a critical yet a relatively understudied area with only limited studies available. Therefore, all possible studies are included in this review regardless of their focus. Whenever possible, comparisons between CMC and face to face situations are offered.

Studies included in this review were first located through a comprehensive search of the literature. Electronic searches were performed on the ERIC (1966-2002), and PsycInfo (1985-2002) databases. Through branching from primary studies and review articles, other citations were also identified. In compiling research reports for this review, the main criterion was inclusive - that is, the educational research literature was examined for reports of research on gender differences whose titles and abstracts suggested that conflict, flaming, and/or harassment were included as a research factor. The research included in this review constitutes a mixture of published 
journal articles and less widely available conference papers, online documents, and doctoral dissertations.

In this review, a theoretical framework adapted from the literature of face to face communication is first depicted. This is followed by a brief overview of gender and discourse pattern, starting with face to face communication and then moving to CMC environments. Next, a discussion of harassment and its legal implication in traditional settings is delineated, to set the stage for the review of harassment in CMC. Subsequently, a review of literature on gender and CMC with a specific focus on conflict and harassment is presented. Finally, comments upon this diverse body of work, recommendations concerning possible areas for future research, and educational implication are offered.

\section{Theoretical framework}

This study is situated at the intersection of the two research models of gender and discourse: the cultural/difference approach (Tannen, 1984), and the view of gender as a performative social construct (Mullany, 2000). The first position can be characterised as "viewing the variation as the product of gender differences in the same way as language variation reflects other cultural and class differences" (Yates, 2001:23). The second position believes that "gender is always a doing... no gender identity behind the expressions of gender... Identity is performatively constituted by the very 'expressions' that are said to be its results" (Butler, 1990:25). Combining these two views, we believe that "masculinity and femininity are not traits that we inherently have, rather they are effects that we perform by the activities we partake in" (Mullany, 2000:3). While fully aware of the existence of dominance and power structure in society, it is believed that the differences implemented in the socialisation process profoundly affect male and female discourses (Maltz \& Borker, 1982; Tannen, 1990, 1994). In addition, it acknowledges that cultural and other social differences such as age, class and ethnicity are important factors in discourse. That is, although there are "norms that govern how individual speakers decide to perform either masculinity or femininity... men and women are fully capable of resisting and subverting these norms" (Mullany, 2000:4).

The cultural/difference approach and the view of gender as a performative social construct are developed focusing on face to face interaction in relation to gender. As suggested in previous research (Yates, 2001), however, it can inform studies about male and female discourse in CMC environments. This review study, therefore, is grounded in these theories, and a discussion of these theoretical stands in CMC settings based on this review of empirical research will be provided in the concluding section. 


\section{Gender and discourse}

\section{Face to face communication}

Although the focus of this study is on CMC, a brief review of the discourse pattern in relation to gender in traditional face to face communication is first provided, to set the stage. In recent decades, gender and language has been an active research line with numerous psychological, sociological and linguistic articles on this issue (eg. Coates, 1986; Graddol \& Swann, 1989; Lackoff, 1975, 1990; Tannen, 1984). Typical patterns can be drawn from these studies and Tannen's overview (1990) concerning male and female communication, though the reasons for these differences remain debateable. To date, most people agree that female language tends to be powerless and uses linguistic strategies such as indirectness, taciturnity, silence and tag questions. Male language, on the other hand, is usually dominant involving linguistic strategies like interruption, volubility, silence, and topic raising (Tannen, 1994). For instance, it is found that females tend to use indirect language to gain the benefits of defensiveness and rapport (Lackoff, 1975). Defensiveness is defined as "a speaker's preference not to go on record with an idea in order to be able to disclaim, rescind, or modify it if it does not meet with a positive response" (Tannen, 1994:32). Many scholars found that males talk more, talk longer, and take more turns than females (Yates, 2001). Research also has consistently found that males are competitive and like to engage in conflict by arguing, issuing commands, and taking opposing stands; whereas females tend to be collaborative and try to avoid conflict. Females, therefore, tend to use agreeing, supporting, and making suggestions rather than commands (Maltz \& Borker, 1982; Tannen, 1994).

In summary, empirical evidence from previous research can be usefully categorised into three forms:

First there is evidence of the inequalities in the structure of male/ female interactions. For instance, ... men have more turns and often speak for longer in mixed gender interactions. When women hold the conversational floor of more than one third of the interaction men will perceive women to be dominating a conversation (Holmes, 1992). Second, there is evidence of gender differences in the linguistic practices and strategies that people use in interactions. These include differences in turn-taking conventions, means of gaining the conversational floor, and means of directing the flow of the interactions. Then there is evidence of differences in the purposes for which people engage in linguistic interaction (Yates, 2001: 23).

These linguistic patterns identified in face to face communication clearly indicate that gender plays an important role. Moving into $\mathrm{CMC}$, with the absence of physical and paralinguistic cues, are the patterns preserved? 
The following section provides an overview of what empirical research has discovered about $\mathrm{CMC}$ and gender.

\section{Computer mediated communication}

In the past 10 years or so, gender and communication in CMC has been explored in various forms and under different conditions. Sample research questions include: In what ways do males and females communicate differently in CMC? How does gender influence communication, social relations and the communicative process? What are the impacts of an individual's gender on group members' use of anonymous, computer mediated collaborative technologies? With respect to gender and language in $\mathrm{CMC}$, previous review papers have provided comprehensive syntheses and extensive summaries (see for example, Herring, 2001; Yates, 2003; Yates, 1997, 2001). Although focusing on conflict and harassment issues in this paper, I fully recognise that there are gender perspectives other than conflict and harassment. For instance, females perceive "deep learning" in online environments and they tend to reject social norms and feel "social isolation", as suggested by researchers (Anderson \& Haddad, 2005; Graddy, 2004). This is, however, beyond the scope of this review. Consequently, only a brief overview of the general pattern related to gender and $\mathrm{CMC}$ interactions is offered next.

Since its introduction, males have dominated the computer (Land, 1999). They have more computer interest and ability, and spend more time with computers (Martinez, 1994). Earlier studies (Pitkow \& Recker, 1994) showed that online networks were predominately used by males, while recent data demonstrated that more and more females were using the Internet - a recent online survey of 6629 users indicated a surprisingly high percentage of females (63.2\%) online (Inter Commerce Corporation, 2003). The increasing number of females using CMC, however, does not guarantee parity. Males rate their computer expertise higher than females (McCoy, Heafner, Burdick \& Nagle, 2001); they are more motivated to acquire CMC skills, and develop less anxiety toward technology (Nachmias, Mioduser \& Shemla, 2000). Others, however, found that females viewed CMC more favourably than males (Hiltz \& Johnson, 1990). Females see computers as more useful than males do, although they are less comfortable using computers (Katz, Maitland, Hannah, Burggraf \& King, 1999).

In CMC settings, most research findings indicate that males tend to write longer and more frequent messages (Herring, 1993; Sussman \& Tyson, 2000; Wood \& Stagner, 1994). Some believe that because females use more nonverbal communication in face to face communication, which is not 
possible in CMC, they tend to contribute less (Briton \& Hall, 1995; Burgoon \& Dillman, 1995).

Comparing CMC and face to face environments, a general conclusion drawn from the literature was that females appear to be at less of a disadvantage in CMC than in face to face meetings (McConell, 1997). The findings about the quantity of participation, however, are contradictory. Some reported that females contributed more to CMC than in face to face interaction (Light, Colbourn \& Light, 1997), whereas others found that females produced more messages in face to face communications than in CMC (Adrianson, 2001).

When comparing online learning with traditional face to face courses, researchers (Anderson \& Haddad, 2005) indicated that female students, compared to their male counterparts, experienced more voice in online environment as compared to face to face courses. This in turn, contributed to the fact that female students, but not male students, experienced deeper perceived learning in online courses than in face to face courses.

\section{Female language}

The general trend found in CMC research indicated, as in face to face communication, that females tend to use language that is powerless in CMC. For instance, it was found that females are least likely to argue (Savicki, Kelley \& Lingenfelter, 1996a, 1996b); act in reactive rather than proactive ways; are verbally dominant only when the males present have an equal status (Roen, Peguesse \& Abordonade, 1995); apologise more often than males, and use explicit justification. Even if females use assertions, they use only attenuated assertions (Hering, 1993).

Female communication is more supportive and rapport building (Herring, 1993), and tends to use "coalition language" (Savicki et al, 1996a, 1996b). Baxter-Magolda (1992) found that females engage in interactivity and rely on the opinions of others to help construct their own knowledge. Blum (1999) reported that females' messages are more empathetic, mention themselves, their families or spouses, and use a cooperative tone.

Females show more personal orientation in their language, which is expressed, for example, by a higher number of addressed messages and personal discussions (Hering, 1993). They use more "I," "me," "my," "myself" statements and generally show more communication apprehension than males (Fishman, 1997; Herring, 1994; Spender, 1995). In addition, they tend to be more expressive, more skilled at sending and decoding nonverbal messages and participate in more non-verbal communication behaviour (Briton \& Hall, 1995). 


\section{Male language}

In contrast, males are found to be authoritatively oriented and this orientation is evidenced through language expressions. Messages sent by males were found to be more confrontational, autonomous, certain, abstract, arrogant and controlling (Blum, 1999). Males use coarser and more abusive language, strong assertions, self promotion, put downs and challenges (Hering, 1993).

Males tend to use fact oriented language (Savicki, Lingenfelter \& Kelley, 1996) and rhetorical questions (Hering, 1993). They use the opinions of others as material for debate (Baxter-Magolda, 1992; Herring, 1993) and are more outcome oriented (Van Hiel \& Schittekatte, 1998). Males' postings, more than females', use humour and/or sarcasm (Herring, 1993) and include calls for action (Savicki et al, 1996a).

Comparing interactions between face to face and CMC settings, males were found to go "off script"; they seemed to be attempting to establish dominance (Guadagno \& Cialdini, 2002). They participated more than females in classroom discussion and called out more answers during class discussion in face to face settings (Hsi \& Hoadley, 1997).

\section{Anonymous interaction}

When anonymity is possible, it is found that females prefer anonymous interaction through CMC because it does not allow judgment on the basis of gender (Gopal, Mirana, Robichaux, \& Bostrom, 1997). Further, anonymity actually leads to increased idea generation (Connolly, Jessup \& Valacich, 1990). If the gender were known, females were perceived to be more cooperative and less exploitative than males (Matheson, 1991; Matheson \& Zanna, 1990).

The gendered communication patterns observed in previous research (Yates, 1997, 2001) suggest that readers can infer the gender of message authors only from the language used in CMC. This judgment of gender online can cause potentially problematic group behaviour such as mistaken behavioural intentions, false perceptions and discrimination, based on the language used (Herring, 1994). Savicki, Kelley \& Oesterreich (1999) examined this issue from a different angle. They explored readers' ability to identify an author's gender when messages were selected for language characteristics identified previously. Recognising the relationship between typical female communication patterns (eg. use of " $\mathrm{I}$ " statements; coalition language; supportive nature; self disclosure) and a high level of satisfaction and group development, the researchers labelled two groups: the high group development communication style (HCS) and low group development communication style (LCS). These two styles were developed 
based on previous empirical studies which suggested that female style bears a strong resemblance to HCS communication and male style to LCS communication (Herring, 1993, 1994; Savicki et al, 1996; Savicki, Kelley \& Oesterreich, 1998). In this study, a total of 39 college students were asked to judge 20 messages in terms of both the authors' gender and the certainty of the accuracy of their judgment. The results indicated that as judges, females were not more accurate, whereas males were not more certain in making such judgments. When all judges were considered, however, it was found that LCS messages were more accurately judged than HCS messages. Judges tended to be more confident about the accuracy of their judgment for messages sent by male authors than by female ones. In other words, the judges' accuracy followed gender stereotypes for male messages but were opposed to the stereotype for female messages.

In conclusion, although any definite conclusion is probably debatable, the general trend derived from the research literature indicates that even when gender identity is disguised, users carry the same socially constructed, gendered behaviour, including the particular interaction patterns, into CMC settings (Lea \& Spears, 1995). In face to face settings, males tend to dominate, control and be violent (Shaffer, Pegalis, \& Cornell, 1992), but is this still true in virtual environments?

\section{Harassment and legal implications}

"Harassment is a term defined by law to refer to many types of behaviour that are found threatening or disturbing, and beyond those that are sanctioned by society" (Wikipedia, n.d.). Harassment can take many forms including sexual, age, and racial harassment. The most frequently referred harassment is, however, sexual harassment, especially the "male harassing female" variety. In legal terms, "sexual harassment is any unwelcome sexual advance or conduct that creates an intimidating, hostile or offensive environment. In real life, sexually harassing behaviour ranges from repeated offensive or belittling jokes to a workplace full of offensive pornography to an outright sexual assault. It can happen to men and women, gay or straight - in other words, sexual harassment is an equal opportunity offense" (NOLO, n.d.).

In most countries, there are laws against harassment. In North America, there are state, or provincial, and federal laws that protect people from harassment and discrimination based on gender, age, and other factors. In the US, the Civil Rights Act forbids harassment at the federal level, and most states have even more strict laws that prohibit harassment. In addition, most educational and corporate settings have their own policies and legal obligations related to harassment. Depending on the degree of severity, criminal charges can be laid for harassment. 


\section{Conflicts, harassment and CMC}

It has been reported in previous research that gender differences emerge in the development and handling of interpersonal conflict. In Western societies, females are expressive and supportive of establishing harmonious relationships, while males tend to be dominant, competitive and unconcerned about socio-emotional or expressive concerns (Shaffer, Pegalis \& Cornell, 1992). In CMC environments, text based name calling, use of coarse language, profanity and personal attacks have been discovered (Kiesler \& Sproull, 1992; Thompsen, 1994). Male appropriation of task roles and preference for authoritative language and strong assertions, as identified in many studies, seem to set the stage for conflict and flaming, which may result in harassment. In this paper, flaming refers to emotionally charged, hostile or insulting postings in CMC environments (Thompsen, 1994).

\section{Conflicts}

In face to face communication, males tend to dominate, control, and aggressive. Moving to CMC environments, however, some interesting results are found. Although few studies have explored conflicts and flaming in relation to gender, during computer mediated communications, the limited available literature is informative. For example, contrary to people's general perceptions, Wolfe (1999) found that both females and males are equally likely to initiate disagreement in CMC. When the ideas are challenged, however, females are more likely than males to drop out of the conversation rather than defend their ideas. Others (Savicki et al, 1996b) found that among female only, male only, and mixed small learning groups of college psychology students, male only groups use argumentative, coarse and abusive language most often.

Conflicts resulted from offending "posts" - those messages sufficiently in violation of normative expectations (Smith, McLaughlin \& Osborne, 1997) and the subsequent events attracted researchers' attention. In some research studies, offending posts are categorised into seven groups: (1) incorrect or novice use of technology; (2) bandwidth piggery; (3) violation of Usenet conventions; (4) violation of newsgroup conventions; (5) ethical violations; (6) inappropriate language; and (7) factual errors (McLaughlin, Osborne \& Smith, 1995). In particular, reproaches have been studied to explore remedial behaviour. For example, it is found that justifications and denials tend to spark more aggravating messages and could escalate conflict (Cody \& McLaughlin, 1990; Smith et al, 1997). Analysing five newsgroup postings, Smith, McLaughlin \& Osborne (1997) examined the pattern of reproaches in CMC. They found that the types of offence set the tone for subsequent correspondents. In terms of gender effect, interesting 
patterns emerged. Male offenders exhibit more sarcastic behaviour, whereas female offenders tend to be more humorous and witty. Females are also more likely to mitigate. They concede errors, provide excuses or justify their behaviour, while males often deny wrongdoing. Same sex reproach occurred most frequently and female reproachers out-posted female offenders.

Another study conducted in New South Wales examined equity issues focusing on adult rural women's experiences in online learning (Meyers, Bennett \& Lysaght (2004). This examination of 16 female students indicated that male students' behaviours were perceived as not conducive to a harmonious communication environment. These female students identified a range of male negative behaviours including personal attacks and sexism. They found that their female colleagues have never written anything controversial, but their male colleagues tended to write controversial issues and harassing statements. How did the female students react to those negative behaviours? Three main strategies were identified: ignoring of the behaviour, posting responses in attempts to curb the behaviours, and withdrawal from further participation in a topic.

Some other studies, however, painted more complex pictures of gender relations and expression of the feminine in particular within CMC environments (Cherny, 1996; Monroe, 1999). Researchers found that CMC provides an environment where both males and females transgress traditional gender boundaries. For instance, “women's use of physically aggressive emotes with male characters is an example of women adapting to the different discourse style in male dominated groups... [however], women on the whole seem to prefer using less violent imagery than men use" (Cherny, 1996). Monroe (1999) studied 14 adult students (11 females and 3 males) who enrolled in a traditional seminar course with an online component. In this course where females outnumbered males and dominated online discussion, the male students came to adopt the topics and tone of the females in the class. One significant instance was that a female student openly challenged a male student and invited conflict online which was the only instance, online or off, any female student challenged anyone. The difference was that female students' communication behaviours were substantially different for online compared with a face to face environment, whilst behaviour for male students was similar, online or offline. Consequently, going back to face to face interaction was awkward and embarrassing for the female students, but this returning was natural for the male students. In another similar course, as Monroe described, a flame war undermined her class community to an unrecoverable degree. It is important to note that students in this course had a balanced gender ratio. These results led Monroe to conclude that CMC "can too easily become the site for agonistic 
display" (p.77). The transgression of the gendered boundaries was not just a function of the online environment, but also a matter of gender and class marked behaviour. She claimed that it was not the gendered modes of communication that changed, rather, it was the people who use those modes have become more 'plastic'. In the online environment, then, the "gendered identity was no longer structured by the usual polarity of public and private male and female. Such boundaries are blurred, leaky, [and] polluted" (p.75).

\section{Harassment}

Many news stories have reported cyber harassment/ bullying incidents all over the world and that both males and females could be victims. For example, in Australia, a nine-year old grade 4 female student received very pornographic emails. Her parents assumed the sender of the emails was an adult. When the source was traced by local police, it was found that the sender was actually her classmate (Thorp, 2004). A 15 year old boy in Quebec, Canada became an unwilling "celebrity when a film he made of himself emulating a Star War's fight scene was posted on the Internet by some classmates. Millions downloaded the two minute clip... He was so humiliated he sought counselling [and dropped out of school], and his family has launched a lawsuit against his tormentors" (Snider \& Borel, 2004).

Aside from the many reported news stories, several surveys have been conducted to explore cyberbullying issues. In a survey conducted in Britain in 2002, it was found that one out of four youngsters aged 11 to 19 has been cyber harassed (National Children's Home, 2002). A study conducted in Canada in 2004 (Li, 2005) showed a similar pattern. An earlier survey conducted in New Hampshire in 2000 found that about 6 percent of youths had an experience of being harassed online (Thorp, 2004).

The general trend that people are increasingly being cyber harassed has inspired researchers to further explore the issue. Once such exploration focused on the gender harassment in CMC environments (Brail, 1996; Collins-Javis, 1997; Dibbell, 1996). Now there are many cyber harassment incidences being reported in various resources. For example, as reported by WHO@, author “Jayne Hitchcock exposed an Internet scam by a group of people calling themselves the Woodside Literary Agency. In retaliation, the agency launched a series of email bombs to her, her husband, and her lawyer. Then, the harassers forged posts in her name to hundreds of newsgroups. The posts indicated that Jayne was interested in having people call or stop by her house to share their sexual fantasies with her. Her home address and phone number were included" (Herring, 2002: 193). Another two incidents occurred in an academic environment. First, in 
November 1995, four male students at Cornell University sent an email message across the Internet entitled "Top 75 reasons why women (bitches) should not have freedom of speech." Some of the misogynistic and violent reasons are: 1) "stupid says as stupid does (and is); 2) when men whistle at them in the street, they should just shut up and obey anyway; 3) if she can't speak, she can't cry rape" (Herring, 2002:194). Second, as reported by Spertus (1996), a web site called "Babes on the web" was developed in 1995 which consisted of unauthorised links to photographs of professional and academic women on the web. This web site was created by an American named Rob Toups who rated those women based on their sexual attractiveness. Many of those women received crude propositions from men who had seen the pictures.

Biber, Doverspike, Baznik, Cober \& Ritter (2002) investigated people's responses to online gender harassment in academic settings compared with traditional face to face forms of harassment. A survey was administered to 270 undergraduate students in the US. The study examined a total of eight potential sexual harassment acts: (1) sexually explicit pictures; (2) content; (3) jokes; (4) misogyny; (5) use of nicknames; (6) requests for company; (7) requests for sexual favours; and (8) comments about dress. The results showed that certain behaviour, such as requests for company, misogyny, the use of sexist nicknames, and comments about dress, were seen as differentially harassing depending on the discourse medium. Participants did not hold more relaxed standards for online behaviour. Rather, they had similar or even more stringent standards for online behaviour. Females perceived online jokes as more harassing than the same behaviour in a face to face environment, while males rated jokes as more harassing in the traditional environment. Females tended to act rather cautiously (in comparison with a face to face setting) in defining the parameters of sexual harassment online. Compared with their male counterparts, they were more stringent in their judgment of behaviour as harassment because they took sexually explicit online pictures, jokes, and requests for company more seriously.

In traditional settings, it was shown that males "are disproportionately the perpetrators, and women disproportionately the victims" (Herring, 2002:188). It has been argued (Allen, 1995; We, 1994) that in CMC environments, sexism and oppression are maintained and even perpetuated, because cyberspace is a male dominated, patriarchal context. As in any other male dominated setting, females are often ridiculed, intimidated or even harassed to leave or comply with the rules of the setting (Fine, 1987; We, 1994). 
Cyber harassment, according to Herring (2002), shows a pattern that is similar to traditional harassment where males tend to perpetrate and females are victims:

Women were the victims in $84 \%$ of online harassment cases, and men the perpetrators in $64 \%$ of cases reported to the organization Working to Halt Online Abuse in 2000-2001. For many female Internet users, online harassment is a fact of life. (p. 188).

In 2001 alone, as many as one third of female children reportedly experience online harassment (Thomas, 2002). As reported in the study of over 1500 youth, females were targeted at about twice the rate of males (Finkelhor, Mitchell \& Wolak, 2000).

In a survey to a females only listserv, one-fifth of 500 subscribers reported that they had experienced online sexual harassment (Brail, 1994). This type of harassment or intimidation took a variety of forms, ranging "from 'flaming' (overt attacks on a person) to highly sexual comments and visual pornography that dehumanise women" (Soukup, 1999) and "seduction under false pretences, electronic stalking, and virtual rape" (Herring, 1995).

In a study of 432 grade 7-9 students in Canada, Beran \& Li (2004) found that about two thirds of the students had heard of some form of cyber harassment occurring. In addition, both males and females reportedly experienced a similar frequency of cyber harassment which was reflected in both harassment and being victimised.

Other people have reported different types of harassment. For instance, a textually enacted "rape" was conducted on a MOO in which a male user controlled two female players' characters to force the performance of sexually degrading actions on themselves (Dibbell, 1996). Another incident occurred in a support MUD for sexual abuse survivors in which a male enacted graphic sexual abuse to all participants (Reid, 1994).

By analysing data gathered from two chatrooms, a sports related (male dominated) and a female based chatroom, Soukup (1999), found that gender is constructed via CMC, and the traditional and stereotypical conception of gender roles is followed. Interestingly, a masculine presence dominated in both chatrooms, regardless of whether the majority of the participants were males or not. Communication styles tend to be argumentative and confrontational, with common use of sexual humour and personal attacks, especially in the sports related chatroom.

On the one hand, as in face to face settings, male chatrooms tend to be a normative realm where gendered standards are developed, negotiated and sustained through censorship. This censorship includes verbal attacks and 
technique strategies (eg. the "ignore closet"). On the other hand, the female chatroom constantly faces the challenge of masculine users' influence and hence finds it difficult to establish, let alone maintain, its own clear, stable rules to guide interaction. In the female based chatroom, masculine participants pursue passive, coy and submissive feminine participants for romantic encounters.

Herring (1999) compared interactions between two forms of CMC, one an asynchronous listserv group with the majority of participants located in North American universities, and the other a public chatroom in which most participants were expatriate, second generation Indians living in English speaking countries. She found, aligned with the possible functions of the two CMC modes, that harassment takes different forms. In the chatroom, technical strategies can be used to shut off females, whereas in the asynchronous mode, language is the only means for harassments. Age and purpose of communication are other factors that affect the nature of verbal harassment. Younger participants with a recreational purpose tend to harass others in a crude, direct and sexually explicit manner; while in older, academic groups, gender harassment is often disguised by an intellectual veneer. Regardless of these differences, however, the ultimate goal of any gender harassment is the same: restricting female users' scope in order to preserve male control and interests. A typical structural schema of online harassment is identified in both groups, suggesting that gender harassment follows a predictable sequence: (from) provocation, harassment, resistance to harassment, escalation of harassment, compliance. All forms of gender harassment involve coercions, in that aversion inducing behaviour is directed against females in order to preserve the harassers' interests.

These examples lead Herring to conclude that the anonymity of CMC "not only fosters playful disinhibition but reduces social accountability, making it easier for users to engage in hostile, aggressive acts" (2001). She further indicated that since harassment targets even females with gender neutral pseudonyms, it suggests that users reveal their gender identity via their interaction style. In fact, synchronous online chat users reveal their gender cues so frequently (on average once every 3-4 lines of text) that it becomes easy for a reader who participates for a relatively long time to identify users' gender (Herring, 1998).

\section{Summary}

In summary, because CMC is a relative new phenomenon, studies exploring gender difference in interaction focusing on flaming and harassment are sparse. While it is difficult to draw broad conclusions based upon this limited research, the research available strongly suggests a 
typical pattern: regardless of whether the majority of users are males or females, CMC is always dominated by males. The "males" and "females" described here are not necessarily referred to the biological gender of the individuals, rather, the gender is "performatively constituted" (Butler, 1990). To maintain CMC as a male domain, females are discriminated against and harassed to fit into male norms. Depending on the demographic group of the users, the level of harassment may vary but the typical pattern remains. This calls for not only more studies to explore the issue of cyber harassment, but also political and legal action (Herring, 1995).

\section{Conclusion and implications}

This paper has presented a review of the literature on gender, communication and $\mathrm{CMC}$ with respect to conflict and harassment that is relatively a new topic in this field. Although only limited studies have been conducted concerning this topic, the results available raised important issues that challenge many of the assumptions we share about CMC, gender and communication, and call for more profound research in the field.

Is CMC a great equaliser? Although research in this field is still scant, it clearly shows that "just because the technology is presented as 'genderless,' though this is very highly debatable, it does not mean that the interactions taking place through the technology will lose any of their complexity nor will the technology strip away existing social structures" (Yates, 2001:32). The focus on content and communicative practices in CMC highlights the possibilities of new gendered identities being constructed through online interactions. These new gendered identities may appear in a different form from the more fixed forms of "real life." In particular, the research reviewed in this paper regarding harassment, along with previous studies (Yates, 2001), leads "one to conclude that the 'democratic' perception of CMC is seriously flawed" (Yates, 2001:32) and further underscores the importance of the inclusion of other social and cultural variables as we study gender issues in the CMC environment.

The theoretical stands described in the "theoretical framework" section indicate that male and female communicate and interact differently, which reflects the power structure of our society. Although both males and females can be victims and perpetrators in relation to cyber harassment, as suggested by Herring, "to ignore the larger gender pattern associated with violence is to miss a basic insight into the social reality of violence as a means of control and intimidation. That is, it tends to be perpetrated downward along a power hierarchy, thereby reinforcing societal gender asymmetries" (2002:188). Even though anonymity is available in CMC 
environments, males like to preserve their gender identity while females tend to disguise it, which further reflects the view that males have power over females. The general economically superior power of males as existing in society permeates to discourse, regardless of the context. As this review demonstrated, just like in face to face discourse, males tend to be competitive, dominant, control, status seeking, using flaming languages, aggressive and hostile in CMC settings. It is important to note that the gender discussed in here regarding online interactions may not linked to the biologically gendered individuals, but rather referred to the gendered behaviours of individuals whose biological gender may well be ambiguous (LeCourt, 1999; Monroe, 1999).

Having said this, it is important to realise that males and females are "fully capable of using strategies associated with either masculinity or femininity" (Mullany, 2000:4), both in CMC and face to face settings. Regardless of the environments, other factors beyond gender, such as culture, age, ethnicity, and class, also play important roles in discourse studies. For example, gender harassment identified in younger listserv groups employed different strategies from those in older, academic groups.

This review of literature demonstrates that gender differences reflected in communication and interaction pattern in CMC settings are similar to those reflected in face to face environments. One issue, however, deserves more serious attention. As discussed by Herring (2001), the anonymity of CMC reduces the social accountability which may result in acceleration of hostile and aggressive acts. It is probable that the power structure in our society not only permeates to language in $\mathrm{CMC}$, but also perpetuates and deteriorates the situation in this virtual environment. For example, the increasing incidence of cyber harassment and cyber bullying reported adds new dimensions to research into discourse and gender studies.

Does CMC have the potential to be a powerful and flexible tool to support equity? The answer is "Yes." Merely installing the hardware and employing the software, however, does not produce the desired outcomes (Li, 2003a, 2003b). Successful and effective learning about the use of CMC in enhancing gender equity must rely on a thorough understanding of gender differences in the CMC context. Only after we have this thorough understanding, can we explore and develop sound teaching and learning strategies (Albright \& Graf, 1992; Coley, Cradleer \& Engel, 2000). This need calls for future research that will allow us to better understand the issue and improve the development and utilisation of CMC.

In general, research in the field is limited. The following is a list of recommendations for future studies, based on what was found in the literature: 
- Solid theoretical foundations are needed in research. While some studies that were reviewed had clear theoretical underpinning, others lacked solid theoretical grounding. Most of the research papers focusing on communication and gender tended to only provide empirical results without offering its theoretical stands. As suggested by some researchers (Eckert \& McConnell-Ginet, 1992; Mullany, 2000), the current lack of a coherent theoretical framework for discourse and gender studies inevitably weakens the explanatory force of the research. Because CMC is a relatively new field, research into theoretical groundings of discourse and gender in this particular context is scarce. One suggestion may be to review pertinent theoretical foundations in traditional face to face settings and compare it with discourse in CMC settings. This may provide useful information to help us adapt and develop new theoretical groundings for this new field of study.

- Quantitative research should use well-established measures and should report clear, reliable and valid information. While numerous quantitative research studies provided useful information that shed light on the existing literature in discourse in relation to gender and $\mathrm{CMC}$, many of them did not provide enough data from which to evaluate its validity. For instance, many authors simply reported a percentage of students who used a particular language function without give any reliability and validity detail. Further, examination of school students with large scale, well-designed, comprehensive research is sparse.

- More research needs to focus on K-12 settings and research on cyber harassment needs to go beyond listserv settings. The great majority of the existing research studies related to discourse, gender and CMC focused on college and adult students or listservs. Particularly, the papers related to violence and harassment were overwhelmingly emphasising listserv environments. This does not indicate that gender, harassment and CMC are unimportant issues in K-12 educational settings. Rather, it calls for more research on studies of K-12 students experience in relation to harassment and CMC, and strategies for providing safe cyberspaces for K-12 educational practices. For example, the research into cyber harassment almost exclusively focuses on listservs from which age and other demographic information are difficult to discern. What about cyber harassment in schools? What are students' perceptions, experience and attitudes toward cyber harassment? As the Internet is increasingly being introduced into K-12 settings, numerous critical questions remain to be answered.

- More research is needed which considers various social and cultural factors. This review of existing literature suggests that the different 
discourse patterns identified in CMC environments attribute to more than just the gender factor. This is also supported by the theoretical view of gender as a performative social construct (Mullany, 2000). Therefore, the exploration of gender issues in interaction and communication in CMC should also consider factors such as age, culture, economic background, and ethnicity. That is, both quantitative and qualitative research is needed to explain the complex interaction of social, cultural and individual factors that shape communication in a CMC environment. Studies that address contextual factors could provide valuable information for the effective use of CMC to promote equity.

\section{Implication for education}

This review of literature focusing on conflict and harassment in CMC environments suggests a number of important issues to be considered.

First, it is evident from this review study that cyber harassment exists and increasingly becomes a serious problem in educational environments. Although many teachers and administrators now recognise the problem of school bullying, few are aware that students are being harassed through electronic communication (Beran \& Li, 2004). Parallel to this lack of awareness by school professionals, researchers have yet to examine the nature of cyber harassment. The growing number and the level of severity of cyber harassment incidents call for our educators, researchers, administrators and authorities to take action. Further, the studies reviewed in this paper suggest that cyberspace tends to be a male dominated field. Appropriately incorporating technology into any educational setting, therefore, needs to consider how females and males communicate and interact as well as how to best serve the needs of both.

Secondly, the nature of new technology enables cyber harassment to occur more secretly, to spread more rapidly, and to be reproduced easily (such as cutting and paste messages). Further, compared to traditional offline harassment in which perpetrators are often considered as socially marginal, perpetrators in cyberspace tend to be average people (Herring, 2002). This makes cyber harassment more problematic than offline harassment because it provides further challenges for us to identify and combat. As suggested by Simmerle,

Anonymity allows those bullies to be more scathing, hurtful and unless the bully makes real and intended threats or repeatedly and personally harasses a student, those that are caught usually cannot be punished by the school or through criminal law; most of this sort of bullying does not take place at school and therefore, the students are not under its jurisdiction (Simmerle, 2003). 
As this review suggests, many of the harassment incidents identified in listservs indicate that males tend to harass, and females are often victims. However, the survey study conducted by Beran \& Li (2004) showed no gender differences in terms of harassing and victimising in high schools. Yet others suggested that females prefer to use electronic communications media such as chatrooms and email to harass or bully others, more than other methods (Thorp, 2004). This not only calls for further research into the area, but also challenges educators, professionals, and administrators to modify appropriate strategies and approaches to combat cyber harassment. Researchers must provide information about its occurrence to inform and support educators and administrators. Rather than focusing on females only as victims, as is in traditional prevention programs, females also need to be considered in the cyber harassment victim cycle and treated holistically. To support the appropriate use of technology in schools, teachers and administrators must be knowledgeable about the extent and various forms of conflict and harassment in cyberspace, and as a result, develop appropriate preventive and intervention strategies to ensure the safety of all students.

Thirdly, the incidence of conflicts and harassment in cyberspace reviewed in this study suggest that cyber harassment is becoming an increasingly critical problem for schools and the whole society. This further stresses the importance of systematic education in safety strategies for both physical and cyber space from an early age, for both boys and girls. This education should be a joint endeavour of schools, families, communities, and the whole of society. It supports the idea that combating harassment and cyber harassment must be considered "at many levels, not only for the individuals themselves, and their families, but also society at large" (Morrison, 2002).

One possible approach to combat this is to increase teacher, administrator and parent awareness of the issues. We also need to encourage them to discuss the issues with students. For schools, establishing a code of conduct that identifies and manages appropriate cyber behaviours may prove to be useful for the development of a safe learning environment. As technology and the Internet are increasingly used in our schools and society, simply advising students to stay away from it will not solve the cyber harassment problem. Rather, adults and students together need to plan and develop initiatives to prevent cyber harassment, that consider a broader context of creating a positive school climate. Professionals providing services to students must be informed about these issues and incorporate them into assessment and intervention. These strategies and approaches need to be monitored and modified to reflect the effective management of this form of harassment to promote responsible use of technology. 
Finally, although no definite conclusion is available, this study of cyber conflict and harassment "sheds light on the larger forces - technological, ideological, and societal - that shape the online environmental as a social space in which 'bad behaviour' occurs" (Herring, 2002:198). This is a first step towards combating cyber harassment, both inside and outside schools.

\section{References}

Adrianson, L. (2001). Gender and computer-mediated communication: Group processes in problem solving. Computers in Human Behavior, 17, 71-94.

Albright, M., \& Graf, D. (1992). Teaching in the Information Age: The Role of Educational Technology. San Francisco: Jossey-Bass Publishers.

Allen, B. (1995). Gender and computer-mediated communication. Sex Roles, 32(7), 557-563.

Anderson, D. \& Haddad, C. (2005). Gender, voice, and learning in online course environments. Journal of Asynchronous Learning Networks, 9(1). http:/ / www.sloan-c.org/publications/jaln/v9n1/pdf/v9n1_anderson.pdf

Baxter-Magolda, M. (1992). Knowing and reasoning in college: Gender-related patterns in students' intellectual development. San Francisco: Jossey-Bass.

Beran, T. \& Li, Q. (2004). Is cyber-harassment a significant problem? A report on children's experiences. Calgary: University of Calgary.

Biber, J., Doverspike, D., Baznik, D., Cober, A. \& Ritter, B. (2002). Sexual harassment in online communications: Effects of gender and discourse medium. CyberPsychology \& Behaviour, 5(1), 33-42.

Blum, K. (1999). Gender differences in asynchronous learning in higher education: Learning styles, participation barriers and communication patterns. Journal of Asynchronous Learning Networks, 3(1). (article withdrawn from JALN at the request of the author)

Brail, S. (1994). Take back the net! On the Issues, Winter, 40-42.

Brail, S. (1996). The price of admission: Harassment and free speech in the wild, wild West. In L. Cherny \& E. Weise (Eds.), Wired-women (pp. 141-157). Seattle, WA: Seal Press.

Briton, N. J. \& Hall, J. (1995). Beliefs about female and male nonverbal communication. Sex Roles, 23, 79-90.

Burgoon, J. K. \& Dillman, L. (1995). Gender, immediacy, and nonverbal communication. In P. Kalbfleisch \& M. Cody (Eds), Gender, power and communication in human relationships (pp. 63-81). Hillsdale, NJ: Erlbaum.

Butler, J. (1990). Gender trouble: Feminism and the subversion of gender identity. NY: Routledge.

Cherny, L. (1996). Gender differences in text-based virtual reality. [viewed 23 May 2005] http: / / bhasha.stanford.edu/ cherny/genderMOO.html

Coates, J. (1986). Women, men and language. London: Longman. 
Cody, M. \& McLaughlin, M. (1990). Interpersonal accounting. In H. Giles \& P. Robinson (Eds), The psychology of tactical communication. Philadelphia, PA: Multilingual Matters Ltd.

Coley, R., Cradleer, J. \& Engel, P. (2000). Computers and the Classroom: The Status of Technology in US Schools. Princeton, NJ: Policy Information Center, Educational Testing Service.

Collins-Javis, L. (1997). Discriminatory messages and gendered power relations in online discussion groups. Paper presented at the Annual meeting of the National Communication Association, Chicago.

Connolly, T., Jessup, L. \& Valacich, J. (1990). Effects of anonymity and evaluative tone on idea generation in computer-mediated groups. Management Science, 36(6), 689-703.

Dibbell, J. (1996). A rape in cyberspace, or how an evil clown, a Haitian trickster spirit, two wizards, and a cast of dozens turned a database into a society. In R. Kling (Ed), Computerization and controversy (2 ed.). NY: Academic Press.

Eckert, P. \& McConnell-Ginet, S. (1992). Communities of practice: Where language, gender and power all live. Paper presented at Locating power: Second Berkeley Women and Language Conference, Berkeley CA.

Fine, G. (1987). One of the boys: Women in male-dominated settings. In M. Kimmel (Ed), Changing men: New directions in research on men and masculinity. CA: Sage.

Finkelhor, D., Mitchell, K., \& Wolak, J. (2000). Online victimization: A report on the nation's youth. http:// www.unh.edu/ccrc/pdf/Victimization_Online_Survey.pdf

Fishman, B. J. (1997). Student traits and the use of computer-mediated communication tools: What matters and why? Paper presented at the Annual meeting of AERA.

Gopal, A., Mirana, S. M., Robichaux, B. P. \& Bostrom, R. P. (1997). Leveraging diversity with information technology: Gender, attitude, and intervening influences in the use of group process. Organizational Behavior and Human Performance, 25, 97-106.

Grabe, M. \& Grabe, C. (2001). Integrating technology for meaningful learning (3 ed.). NY: Houghton Mifflin.

Graddol, D. \& Swann, J. (1989). Gender voices. Oxford: Basil Blackwell.

Graddy, D. (2004). Gender and online discourse in the principles of economics. Journal of Asynchronous Learning Networks, 8(4), 3-14. http: / / www.sloanc.org/publications/jaln/v8n4/pdf/v8n4_graddy.pdf

Guadagno, R. E. \& Cialdini, R. B. (2002). Online persuasion: An examination of gender differences in Computer-Mediated Interpersonal Influence. Group Dynamics, 6(1), 38-51.

Herring, S. (1993). Gender and democracy in computer-mediated communication. Electronic Journal of Communication, 3(2), 1-17.

Herring, S. (1994). Gender differences in computer mediated communication: Bringing familiar baggage to the new frontier. Paper presented at the American Library Association Annual Convention, June, Miami, FL. 
Herring, S. (1995). Net work: Freedom of speech or freedom of harassment? The College, 1(1), 8-9.

Herring, S. (1998). Virtual gender performances. Paper presented at the Talk at Texas A\&M University, Texas.

Herring, S. (1999). The rhetorical dynamics of gender harassment online. The Information Society, 15, 151-167.

Herring, S. (2001). Gender and power in online communication. Center for Social Informatics Working Papers.

Herring, S. (2002). Cyber violence: Recognizing and resisting abuse in online environments. Asian Women, 14, 187-212.

Hiltz, R. S. \& Johnson, K. (1990). User satisfaction with computer-mediated communication systems. Management Science, 36, 739-751.

Holmes, J. (1992). Women's talk in public contexts. Discourse and Society, 3(2), 131150.

Hsi, S. \& Hoadley, C. M. (1997). Productive discussion in science: Gender equity through electronic discourse. Journal of Science Education and Technologies, 6(1), 23-36.

Inter Commerce Corporation (2003). Survey.net. [viewed 25 June 2003] http: / / www.survey.net/ content0r.html

Katz, L., Maitland, M., Hannah, R., Burggraf, K. \& King, S. (1999). The effects of gender and academic program on learning styles and attitudes of undergraduate students using multimedia, web-based anatomy labs. Paper presented at the 10th International Conference on College Teaching and Learning, Jacksonville, FL.

Kiesler, Siegel, J., \& McGuire, T. (1984). Social psychological aspects of computermediated communication. American Psychologist, 39, 1123-1134.

Kiesler, S. \& Sproull, L. (1992). Group decision making and communication technology. Special Issue: Group decision making. Organizational Behavior and Human Decision Processes, 52, 96-123.

Lackoff, R. (1975). Language and women's place. NY: Harper Row.

Lackoff, R. (1990). Talking power. NY: Basic Books.

Land, M. J. (1999). Evidence of gender disparity in children's computer use and activities. Paper presented at the Annual Meeting of the Association for Education in Journalism and Mass Communication, New Orleans, LA.

Lea, M. \& Spears, R. (Eds). (1995). Love at first byte? Building personal relationships over computer networks. CA: Sage.

LeCourt, D. (1999). Writing (without) the body: Gender and power in networked discussion groups. In K. Blair \& P. Takayoshi (Eds), Feminist cyberscapes: Mapping gendered academic spaces (pp. 153-176). Stamford, Connecticut: Ablex Publishing Corporation.

Li, Q. (2002). Interaction and communication: An examination of gender differences in elementary student mathematics and science learning using CMC. Journal of Educational Technology Systems, 30(3), 403-426. 
Li, Q. (2002a). Gender and computer-mediated communication: An exploration of elementary students' mathematics and science learning. Journal of Computers in Mathematics and Science Teaching, 21(4), 341-359.

Li, Q. (2003a). Integrating Internet into teacher education: What works? Paper presented at the annual conference of the American Educational Research Association (AERA). Chicago.

Li, Q. (2003b). Would we teach without technology? A professor's experience of teaching mathematics education incorporating the Internet. Educational Research (NFER), 45(1), 61-77.

Li, Q. (2005). Cyberbullying in schools: Nature and extent of adolescents' experience. Paper presented at the Annual American Educational Research Association Conference, Montreal.

Light, P., Colbourn, C. \& Light, V. (1997). Computer mediated tutorial support for conventional university courses. Journal of Computer Assisted Learning, 13, 228235.

Maltz, D. \& Borker, R. (1982). A cultural approach to male-female miscommunication. In J. Gumperz (Ed.), Language and Social Identity (pp. 196216). Cambridge: Cambridge University Press.

Martinez, M. E. (1994). Access to information technologies among school-age children: Implications for a democratic society. Journal of the American Society for Information Science, 45, 395-400.

Matheson, K. (1991). Social cues in computer-mediated negotiations: Gender makes a difference. Computers in Human Behaviour, 7(3), 137-145.

Matheson, K. \& Zanna, M. T. (1990). The focus is on me. Social Science Computer Review, 8, 1-12.

McConell, W. (1997). Interaction patterns in mixed sex groups in educational computer conferences. Gender and Education, 9(3), 345-363.

McCoy, L. P., Heafner, T. L., Burdick, M. G. \& Nagle, L. M. (2001). Gender differences in computer use and attitudes on a ubiquitous computing campus. Paper presented at the Annual Meeting of AERA, Seattle, Washington USA.

McLaughlin, M., Osborne, K. \& Smith, C. (1995). Standards of conduct on Usenet. In S. Jones (Ed), Cybersociety (pp. 90-111). CA: Sage.

Meyers, W. Bennett, S. \& Lysaght, P. (2004). Asynchronous communication: Strategies for equitable e-learning. In R. Atkinson, C. McBeath, D. Jonas-Dwyer \& R. Phillips (Eds), Beyond the comfort zone: Proceedings of the 21st ASCILITE Conference (pp. 655-662). Perth, 5-8 December. http:/ / www.ascilite.org.au/conferences/perth04/procs/meyers.html

Monroe, B. (1999). Re-membering mama: The female body in embodied and disembodied communication. In K. Blair \& P. Takayoshi (Eds), Feminist cyberscapes: Mapping gendered academic spaces (pp. 63-82). Stamford, Connecticut: Ablex Publishing Corporation.

Morrison, B. (2002). Bullying and victimisation in schools: A restorative justice approach. Trends and Issues Series. Australian Institute of Criminology. http: / / www.aic.gov.au/publications/tandi/ti219.pdf 
Mullany, L. (2000). The application of current language and gender theory to managerial meeting discourse. Nottingham Linguistic Circular, 15, 1-16.

Nachmias, R., Mioduser, D. \& Shemla, A. (2000). Internet usage by students in an Israeli high school. Journal of Educational Computing Research, 22(1), 55-73.

National Children's Home (2002). NCH 2002 Survey, 2004-07-15 http: / / www.nch.org.uk/itok/ showquestion.asp?faq=9\&fldAuto=145

NOLO. (n.d.). Fighting sexual harassment. [verified 28 Aug 2005] http:/ / www.nolo.com/lawcenter/ ency/article.cfm/ObjectID/0E020B2A-F7D9-40C2AB52398DFAAFDC6F / catID / 57153B2E-F39E-48DA-830ADA31F5A23325

Pitkow, J. E. \& Recker, M. (1994). Using the Web as a survey tool: Results from the Second WWW User Survey. Journal of Computer Networks and ISDN Systems, 27(6).

Reid, E. (1994). Cultural formations in text-based virtual realities. Unpublished Master's thesis, University of Melbourne, Melbourne.

Roen, D. H., Peguesse, C. \& Abordonade, V. (1995). Gender and language variation in written communication. In D. 1.-. Rubin (Ed.), Composing social identity in writing language. Hilldale, NJ: Earlbaum.

Savicki, Kelley, M., \& Oesterreich, E. (1999). Judgments of gender in computermediated communication. Computers in Human Behavior, 15, 185-194.

Savicki, Lingenfelter, D. \& Kelley, M. (1996). Gender language style and group composition in internet discussion groups. Journal of CMC, 2(3).

Savicki, V., Kelley, M. \& Lingenfelter, D. (1996a). Gender, group composition and task type in small task groups using computer mediated communication. Computers in Human Behavior, 12, 549-565.

Savicki, V., Kelley, M. \& Lingenfelter, D. (1996b). Gender and group composition in small task groups using computer-mediated communication. Computers in Human Behavior, 12(2), 209-224.

Savicki, V., Kelley, M., \& Oesterreich, E. (1998). Effects of instructions on computermediated communication in single- or mixed-gender small task groups. Computers in Human Behanvior, 14, 163-180.

Shaffer, D. R., Pegalis, L. J. \& Cornell, D. P. (1992). Gender and self-disclosure revisited: Personal and contextual variations in self-disclosure to same-sex acquaintances. Journal of Social Psychology, 132, 307-315.

Simmerle, M. (2003). Cyber Bullying. [viewed 15 Jul 2004] http: / / www.imakenews.com/psla/e_article000127654.cfm

Smith, C., McLaughlin, M. \& Osborne, K. (1997). Conduct control on Usenet. Journal of Computer-Mediated Communication, 2(4), 1-11.

Snider, M. \& Borel, K. (2004). Stalked by a cyberbully. Macleans.ca, 24 May. http:/ / www.macleans.ca/topstories/technology/article.jsp?content=20040524_81183_81183

Soukup, C. (1999). The gendered interactional patterns of computer-mediated chatrooms: A critical ethnographic study. The Information Society, 15, 169-176.

Spender, D. (1995). Nattering on the net: Women, power and cyberspace. North Melbourne, Australia: Spinifex Press Ltd. 
Spertus, E. (1996). Social and technical means for fighting on-line harassment. http: / / www.mit.edu/people/ellens/Gender/glc

Sussman, N. M. \& Tyson, D. H. (2000). Sex and power: Gender differences in computer-mediated interactions. Computers in Human Behavior, 16, 381-394.

Tannen, D. (1984). Conversational style: Analyzing talk among friends. Norwood: Ablex.

Tannen, D. (1990). You just don't understand: Women and men in conversation. NY: William Morrow.

Tannen, D. (1994). Gender and discourse: Featuring a new essay on talk at work. New York: Oxford University Press.

Thomas, K. (2002). Girls know way around Net, parents. USA Today, 13 February.

Thompsen, P. (1994). An episode of flaming: A creative narrative. Etc., 51, 51-72.

Thorp, D. (2004). Cyberbullies on the prowl in schoolyard. [viewed 15 Jul 2004] http: / / australianit.news.com.au/articles / 0,7204,9980900^15322^^nbv^15306,00.html

Van Hiel, A. \& Schittekatte, M. (1998). Information exchange in context: Effects of gender composition of group, accountability, and intergroup perception on group decision making. Journal of Applied Social Psychology, 28, 2049-2067.

We, G. (1994). Cross-gender communication in cyberspace. Arachnet Electronic Journal on Virtual Culture, 2(3). http:/ / feminism.eserver.org/ cross-gender-comm.txt

Wikipedia (n.d.). http: / / en.wikipedia.org/wiki/

Wolfe, J. (1999). Why do women feel ignored? Gender differences in computermediated classroom interactions. Computers and Composition, 16(1), 153-166.

Wood, W. \& Stagner, B. (1994). Why are some people easier to influence than others? In S. Shavitt \& T. C. Brock (Eds.), Persuasion (pp. 149-174). Boston: Allyn \& Bacon.

Yates, J. (2003). Interactive distance learning in preK-12 settings: A handbook of possibilities. Westport, Connecticut: Libraries Unlimited.

Yates, S. (1997). Gender, identity, and CMC. Journal of Computer Assisted Learning, 13, 281-290.

Yates, S. (2001). Gender, language and CMC for education. Learning and Instruction, $11,21-34$.

Dr Qing Li, Assistant Professor, Faculty of Education, University of Calgary, Calgary AB, Canada T2N 1N4. Email: Email: qinli@ucalgary.ca Web: http:/ / www.ucalgary.ca/ qinli / 